
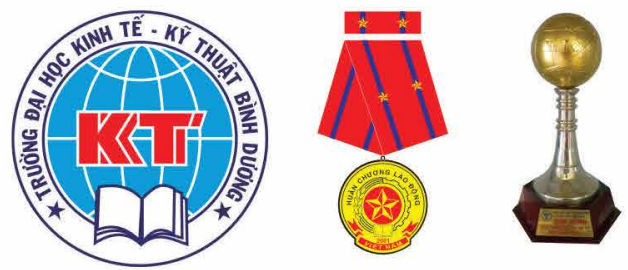

ISSN:0866 - 7802

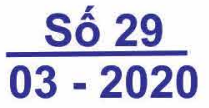 \\ 3 THÁNG 1 KỲ
}

Tạp chí

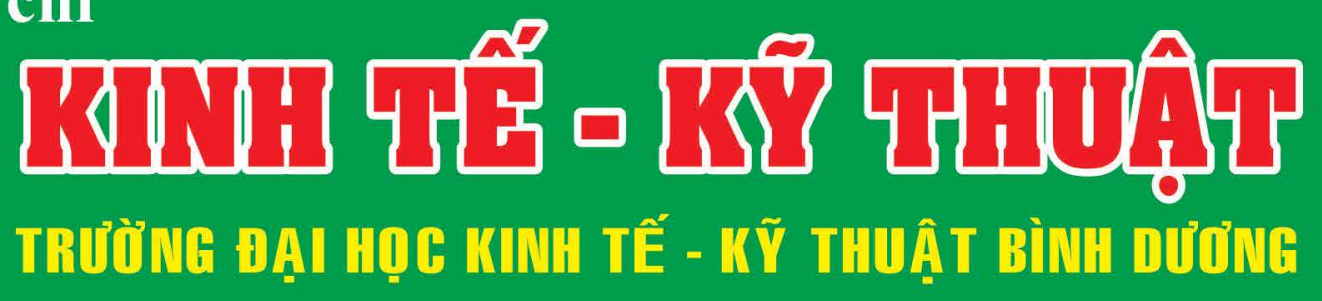

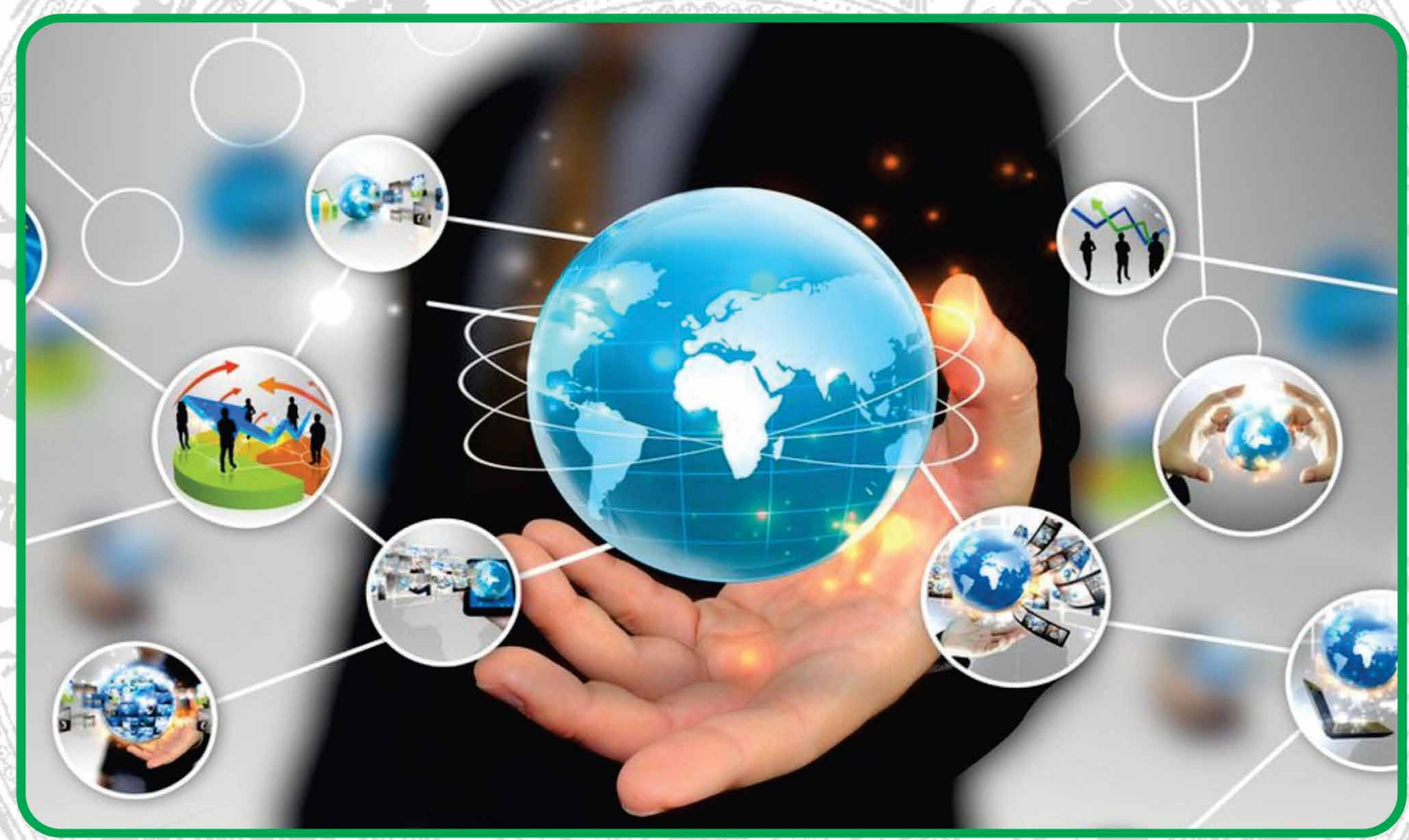



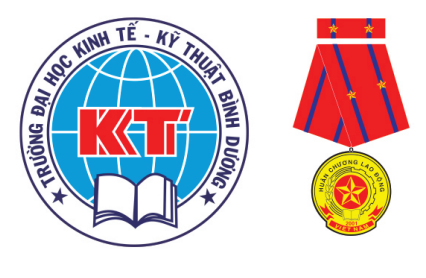

Tòa soạn \& trị sự:

530 Đại lộ Bình Dương, Phường Hiệp Thành, TP. Thủ Dầu Một, Tỉnh Bình Dương

Email: tapchiktktbd@gmail.com

\section{Tổng Biên tập
PGS.TS.NB. Nguyễn Thanh
$\star$
Phó Tổng Biên tập
TS.NB. Trần Thanh Vũ \\ Hội đồng Biên tập Chủ tịch: \\ TS.NB. Lê Bích Phương \\ Các ủy viên:}

GS.TS.DS. Nguyễn Văn Thanh GS.TS. Hoàng Văn Châu

\section{GS.TS. Hồ Đức Hùng}

GS.TS. Hoàng Thị Chỉnh

PGS.TS. Nguyễn Mạnh Hùng

PGS.TS. Đỗ Linh Hiệp

PGS.TS. Nguyễn Quốc Tế

PGS.TS. Phạm Văn Dược

PGS.TS. Phương Ngọc Thạch

PGS.TS. Võ Văn Nhị

PGS.TS. Phước Minh Hiệp

PGS.TS. Phùng Đình Mẫn

PGS.TS. Phạm Minh Tiến

TS. Nguyễn Hữu Thân

TS. Nguyễn Tường Dũng

TS. DS. Trịnh Việt Tuấn

$$
\star \star
$$

Thư ký Tòa soạn:

ThS. Trịnh Hoàng Xuân Phúc

$$
\star \star \star
$$

Giấy phép Hoạt động Báo chí in Số: 36/GP-BTTTT cấp ngày

$$
\text { 05/02/2013 }
$$

Số lượng in: 2.000 cuốn

$$
\star \star \star \star
$$

Chế bản và in tại Nhà in: Liên Tường, Quận 6, Tp.HCM

\section{MỤC LỤC}

Trang

\section{Kinh tế}

01. Hà Nam Khánh Giao, Trân Thị Ngọc Lan: Về ý định chọn học truiơng Cao đảng nghề Hòa Bình Xuân Lộc

02. Nguyễn Duy Mậu: Giải pháp hoàn thiện năng lưc cạn tranh của các doanh nghiệp sản xuất và tiêu thu cà phê trên địa bàn tỉnh Lâm Đông

03. Huỳnh Văn Hải Bằng, Nguyễn Văn Nguyện: Nhũ̃ng yếu tố tác động và giải pháp giảm nghèo trên địa bàn huyện Vũng Liêm, tinh Vinh Long

04. Nguyễn Tấn Danh: Các yếu tố ảnh hưởng dến giá trị thuiơng hiệu trường Cao đảng Kinh tế Đối ngoại

05. Nguyễn Hoàng Chung, Nguyễn Ngọc Giàu: Đạo đức nghê nghiệp của sinh viên chuyên ngành kế toán trong cuộc cách mạng công nghiệp 4.0: nghiên cứu thực nghiệm tại trường Đại học Kinh tế-Kỹ thuạt Bình Dương

06. Vũ Văn Thực: Xây dựng và quảng bá thương hiệu du lịch đông bằng sông Cửu Long

07. Nguyễn Hoàng Phương, Lương Thị Thúy Lành: Một số giải pháp về quản lý nhà nước ngành du lịch tại tỉnh Đồng Nai trong nên kinh tế thị trường

08. Đỗ Lâm Hoàng Trang: Thực trạng gắn kết tăng trưởng kinh tế với công bằng xã hội trong nền kinh tế thị trường định hướng xã hội chủ nghĩa ở Việt Nam

09. Tôn Thất Viên, Trần Thanh Vũ: Nghiên cứu các yếu tố ảnh hưởng dến động lực làm việc của nhân viên ban dư án nhiệt diện PTSC

10. Vương Thị Thanh Nhàn: Vai trò của kiểm toán hệ thống thông tin kế toán trong thời đại công nghiệp 4.0

11. Nguyễn Thị Hồng Ânh, Nguyễn Thị Thùy Ngân: Phát triên dịch vu khách hàng cao cấp tại các ngân hàng thuiơng mại trên địa bàn thành phố Hồ Chí Minh

\section{Nghiên cứu - Trao đổi}

12. Nguyễn Thị Phương Nam: Đào tạo nguồn nhân lực đáp úng yêu 101 câuu phát triên nên kinh tế tri thức trên địa bàn thành phố Hồ Chí Minh

13. Hồ Xuân Thăng: Nhận diện tính khoa học trong việc áp dưng 110 án lệ giải quyết tranh chấp về hợp đông tín dụng - một điên hình thực tiễn cải cách hoạt dộng tư pháp hiện nay ở Việt Nam

14. Nguyễn Khánh Vân: Cơ hội và thách thức cho doanh nghiệp 121 Việt Nam trong bối cảnh mới tù khi Luật doanh nghiệp 2014 có hiệu luic

15. Lê Nho Minh: Quan điêm của Minh Mang về an sinh xã hội và 128 việc thực hiện an sinh xã hội ở thành phố Hồ Chí Minh

16. Hoàng Xuân Sơn, Lê Thị Ái Nhân: Cuộc cách mạng công nghiệp 136 lân thư tư với đổi mới mô hình tăng trưởng kinh tế ở Việt Nam 


\section{Editorial Office and management:}

530 Binh Duong Avenu, Hiep Thanh Ward, Thu Dau Mot City, Binh Duong Province

Email: tapchiktktbd@gmail.com

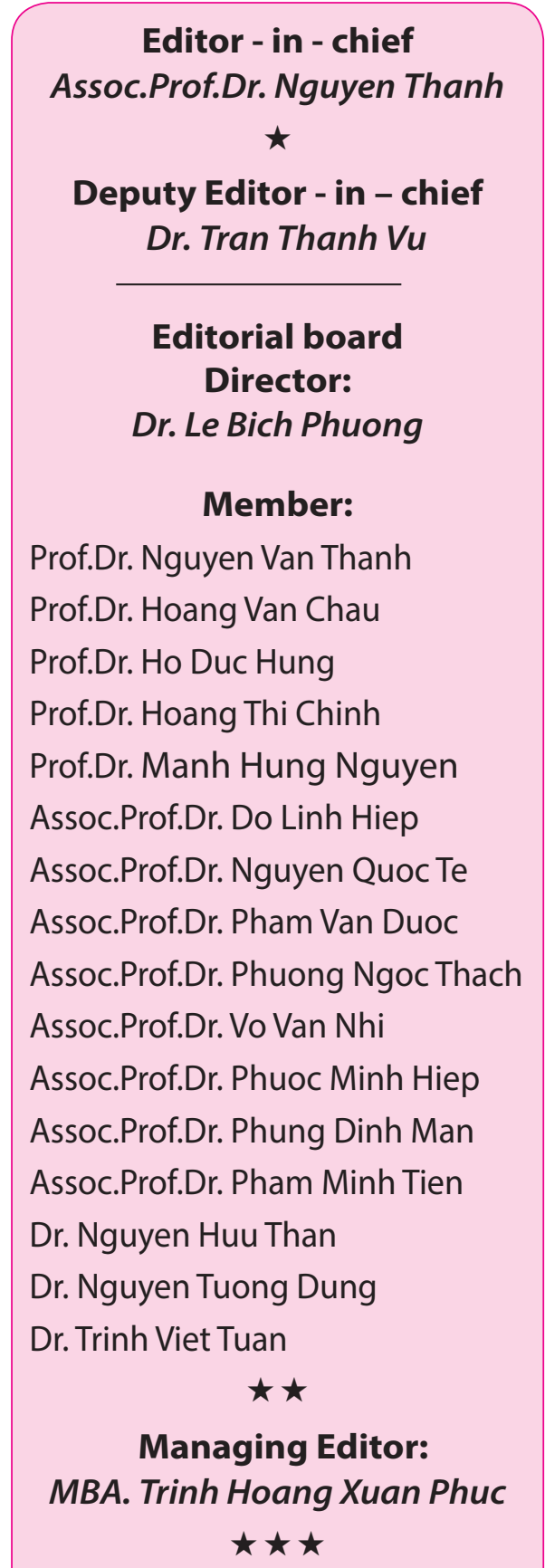

Publishing licence: Studying and following the No: 36/GP-BTTTT Date 05/02/2013

In number: 2.000 copies

$$
\star \star \star \star
$$

Printing at: Lien Tuong printing, District 6, HCM city

\section{TABLE OF CONTENNTS}

Page

\section{Economic}

01. Ha Nam Khanh Giao, Tran Thi Ngoc Lan: About the intention to choose Hoa Binh Xuan Loc vocational college to study

02. Nguyen Duy Mau: Solutions to improve the competitiveness of coffee production and consumption enterprises in Lam Dong province

03. Huynh Van Hai Bang, Nguyen Van Nguyen: Impact factors and solutions for poverty reduction in Vung Lien district, Vinh Long province

04. Nguyen Tan Danh: The factors affecting the brand equity of college of Foreign Economic Relations

05. Nguyen Hoang Chung, Nguyen Ngoc Giau: Professional ethics of accouting students in the fourth industrial revolution: the evidence at Binh Duong Economics \& Technology university

06. Vu Van Thuc: Building and promoting tourism brand in the Mekong delta

07. Nguyen Hoang Phuong, Luong Thi Thuy Lanh: Some solutions on state management for tourism in the Dong Nai province in the market economy

08. Do Lam Hoang Trang: Social justice in the market economy socialist orientation in Vietnam

09. Ton That Vien, Tran Thanh Vu: Researching factors affecting the working efficiency of people's committee of PTSC thermal power project

10. Vuong Thi Thanh Nhan: Benerfits of auditing the accounting information system in the industrial revolution 4.0

11. Nguyen Thi Hong Anh, Nguyen Thi Thuy Ngan: Developing premium customer service at commercial banks on the Hochiminh city

\section{Research - Exchange}

12. Nguyen Thi Phuong Nam: Training human resources to meet 101 the requirements for developing knowledge economic region in Hochiminh city

13. HoXuan Thang: Scientific identification of the science application 110 of the dispute resolution of credit contracts - a practical situation of implementing the current judicial activities in Vietnam

14. Nguyen Khanh Van: Opportunities and challenges for 121 Vietnamese enterprises in the new background when enterprise law in 2014 effective

15. Le Nho Minh: The network's viewpoints about social security 128 and the implementation of social security in Hochiminh city

16. Hoang Xuan Son, Le Thi Ai Nhan: The fourth industrial 136 revolution with innovation of the model of economic growth in Vietnam 


\title{
Kinh tế
}

\section{VỀ Ý ĐỊNH CHỌN HỌC \\ TRƯỜNG CAO ĐĂNG NGHỀ HÒA BÌNH XUÂN LỘC}

Hà Nam Khánh Giao*, Trần Thị Ngọc Lan **

\section{TÓM TÁT}

Nghiên cưu được thực hiện nhằm đánh giá các yếu tố tác động đến ý định chọn học truờng Cao đẳng nghề Hòa Bình Xuân Lộc của sinh viên, thông qua việc khảo sát 450 sinh viên. Phần mềm SPSS 20.0 được sử dụng để xủ lý số liệu thông qua các công cụ: thống kê mô tả, kiểm định độ tin cậy của thang đo thông qua hệ số Cronbach's Alpha, phân tích nhân tố khám phá EFA, phân tích hồi quy bội, kiểm định sụ khác biệt.

Kết quả xủ lý hồi quy bội cho thấy có 03 thành phần tác động đến ý định chọn trương của sinh viên, tù mạnh nhất giảm dần: biến Chi phí và chương trình. Thông tin ngoại tuyến và cơ sở vật chất, Các ý kiến. Nghiên cứu cũng chỉ ra không có sụ khác biệt về ý định chọn trương theo giới tính và tôn giáo. Tù đó, nghiên cứu đề xuất một số hàm ý quản trị để nâng cao ý định chọn học trường Cao đẩng nghề Hòa Bình Xuân Lộc

Từ khóa: ý định, sinh viên, chọn học, trương cao đẳng nghề Hòa Bình Xuân Lộc

\section{ABOUT THE INTENTION TO CHOOSE HOA BINH XUAN LOC VOCATIONAL COLLEGE TO STUDY}

\begin{abstract}
This research aims to measure the factors affecting the students' intention to choose Hoa Binh Xuan Loc vocational College to study, by interviewing 450 students. Cronbach's alpha, exploratory factor analysis and linear regression model and difference testing were used.

The result shows that there are 3 factors affecting the the students' intention to choose Hoa Binh Xuan Loc vocational College to study: (1) Price and Program, (2) Offline information and Facilities, (3) Opinions. The result also shows that there are no difference of Gender and Religions on the intention. This reseach suggests some recommendations for management to enhance the intention to choose this College.
\end{abstract}

Keywords: intention, students, to choose to study, Hoa Binh Xuan Loc vocational College

* PGS. TS. Khoa Vận tải Hàng không, Học viện Hàng không Việt Nam. ĐT: (84) 903306363

E-mail:khanhiaohn@yahoo.com

** ThS. Giảng viên truờng Cao đẳng nghề Hòa Bình Xuân Lộc, ĐT: (84) 907967327

Email: sonattngoclan@yahoo.com 


\section{GIÓ́I THIỆ}

Ngày nay, một trong những yếu tố quyết định khả năng cạnh tranh của các trường là chất lượng đào tạo và tỷ lệ sinh viên tốt nghiệp có việc làm ổn định. Áp lực cạnh tranh trong môi trường giáo dục đã dẫn đến các tổ chức đào tạo sử dụng nhiều cách thức từ thụ động sang tiếp cận thị trường một cách tích cực hơn. Bên cạnh đó, người học ngày nay phải đối mặt với nhiều thông tin tuyển sinh của các trường Đại học, Cao đẳng, khiến họ khó khăn trong vấn đề lựa chọn ngành học, trường học một cách chính xác và hiệu quả. Vấn đề chọn trường không còn là vấn đề riêng của mỗi học sinh mà trở thành vấn đề được gia đình và xã hội quan tâm để định hướng một cách hiệu quả những học sinh cuối cấp tham gia vào những tổ chức đào tạo có uy tín, chất lượng đáp ứng được kỳ vọng của bản thân, gia đình và xã hội.

Thành lập từ năm 2008, Trường Cao đẳng nghề Hòa Bình Xuân Lộc là mô hình giáo dục công giáo tham gia vào hoạt động đào tạo nghề, với mục tiêu "thăng tiến toàn diện con người”, Trường Hòa Bình là nơi thực hiện các vai trò bảo trợ xã hội: chăm sóc nuôi dưỡng, dạy nghề cho các đối tượng có hoàn cảnh khó khăn, yếu thế vẫn có cơ hội học tập để phát triển bản thân, vươn lên trong cuộc sống và hòa nhập với cộng đồng. Trường hoạt động tại địa bàn tỉnh Đồng Nai, mỗi năm thu hút hơn 700 học viên thuộc tỉnh và các khu vực lân cận theo học. Hiện nay, sự cạnh tranh trong lĩnh vực giáo dục ngày càng trở nên gay gắt, vì vậy, để hoàn thành sứ mệnh và mục tiêu đã đề ra, Trường Cao đẳng nghề Hòa Bình Xuân Lộc cần tìm hiểu nhiều hơn nữa các nhu cầu của các học sinh tiềm năng để thu hút và duy trì, góp phần tăng vị thế của trường trong lĩnh vực giáo dục và khẳng định vai trò của trường đối với xã hội, đó cũng chính là mục tiêu của nghiên cứu này.

\section{CƠ SỞ LÝ THUYẾT}

\subsection{Mô hình trường Công giáo dạy nghề}

Mô hình trường Công giáo dạy nghề là mô hình đào tạo giáo dục ngoài công lập trực thuộc các tổ chức Công giáo. Mô hình này còn khá mới mẻ tại Việt Nam, tuy nhiên ở các nước phát triển thuộc khu vực Châu Âu, Châu Mỹ đặc biệt tại Mỹ thì mô hình này khá phổ biến đã được phát triển từ rất lâu đời khoảng hơn 200 năm (Garett, 2006) và được xã hội công nhận về chất lượng đào tạo.

\section{2. Ý định chọn trường của sinh viên}

Nhiều nghiên cứu có liên quan đến lãnh vực giáo dục trong thời gian dài (Hà Nam Khánh Giao, 1998), trong đó có một lượng tài liệu đáng kể được sinh viên xem xét sử dụng trong quá trình đưa ra các quyết định của mình trong việc lựa chọn các trường học (Alexander \& Eckland, 1975, Chapman \& Jackson, 1987, Hossler \& Gallagher, 1987). Quá trình lựa chọn trường đại học, cao đẳng rất phức tạp và liên quan nhiều đến sự tương tác giữa các yếu tố bao gồm chủng tộc/dân tộc, tình trạng kinh tế xã hội, giới tính, trình độ giáo dục của phụ huynh, nguyện vọng của giáo viên và cố vấn, hiệu quả học tập và khả năng tài chính (Alexander \& Eckland, 1975; Chapman \& Jackson, 1987; Hossler \& Gallagher, 1987; Sewell và cộng sụ, 1969).

Chapman \& Jackson (1987) cho rằng việc lựa chọn học tại một trường đại học, cao đẳng là quá trình gồm ba giai đoạn: (1) Giai đoạn nhận thức: nhận thức của cha mẹ, đặc điểm các trường đại học, cao đẳng và các yếu tố nội bộ khác ảnh hưởng đến nhận thức của học sinh đối với trường đại học, cao đẳng, (2) Giai đoạn đánh giá: từ những nguồn ảnh hưởng này, sinh viên phát triển ý thức về giá trị của các trường cụ thể. Đó là giai đoạn sinh viên bắt đầu tạo ra sự ưa thích đối với một số trường so với các trường khác, (3) Giai đoạn lựa chọn: cuối cùng, sở thích về trường học cùng với những ràng buộc về tài 
chính, hoàn cảnh cụ thể sẽ ảnh hưởng đến sự lựa chọn của học sinh.

Hossler \& Gallagher (1987) cũng trình bày sự lựa chọn trường đại học, cao đẳng là quá trình gồm ba giai đoạn tương tự như của Chapman \& Jackson (1987), được trích dẫn rộng rãi trong các tài liệu giáo dục: (a) Phát triển các động lực học đại học: học sinh phát triển một tập hợp lựa chọn các trường đại học, cao đẳng và giới hạn chúng lại dựa trên ảnh hưởng của địa phương, (b) Tìm kiếm các tổ chức tiềm năng: các tổ chức tiềm năng có đặc điểm tương tự với sở thích của họ, (c) Lựa chọn giữa các đối thủ cạnh tranh tổ chức: học sinh chọn từ các tổ chức được ưa thích dựa trên nhận thức về chất lượng trường học, tổng chi phí và các chính sách hỗ trợ tài chính.

\subsection{Một số nghiên cứu về ý định chọn trường của sinh viên}

Bảng 1 tổng hợp một số nghiên cứu nước ngoài và trong nước có liên quan đến việc chọn trường cao đẳng của sinh viên.

Bảng 1: Tổng hợp một số nghiên cứu trước có liên quan

\begin{tabular}{|c|c|c|c|}
\hline TT & Tác giả & Tên đề tài & Kết quả nghiên cứu \\
\hline 1 & $\begin{array}{l}\text { Chapman } \\
(1981)\end{array}$ & $\begin{array}{l}\text { "A model of student } \\
\text { college choice" }\end{array}$ & $\begin{array}{l}\text { - Nhóm yếu tố cá nhân (tình trạng kinh tế, kỳ vọng } \\
\text { đối với giáo dục, chất lượng đào tạo trung học phồ } \\
\text { thông). } \\
\text { - Nhóm yếu tố ảnh hưởng bên ngoài (cá nhân ảnh } \\
\text { hưởng, đặc điểm cố định của trường, nố lực giao tiếp } \\
\text { với sinh viên) }\end{array}$ \\
\hline 2 & $\begin{array}{l}\text { Henry } \\
(2012)\end{array}$ & $\begin{array}{l}\text { "Understanding the } \\
\text { college choice process of } \\
\text { catholic homeschooled } \\
\text { students" }\end{array}$ & $\begin{array}{l}\text { - Cha mẹ (thu nhập, trình độ học vấn, sự khuyến khích } \\
\text { và hô̂ trợ) } \\
\text { - Bản thân sinh viên (khả năng học tập, khát vọng học } \\
\text { tập, giới tính) } \\
\text { - Đặc điểm thể chế (danh tiếng, vị trí, chi phí, tôn giáo) }\end{array}$ \\
\hline 3 & $\begin{array}{l}\text { Dao \& } \\
\text { Thorpe } \\
(2015)\end{array}$ & $\begin{array}{l}\text { "What factors influence } \\
\text { Vietnamese students" } \\
\text { choice of university?" }\end{array}$ & $\begin{array}{l}\text { - Cơ sở vật chất và dịch vụ } \\
\text { - Chương trình đào tạo } \\
\text { - Chi phí } \\
\text { - Thông tin ngoại tuyến } \\
\text { - Các ý kiến } \\
\text { - Thông tin trực tuyến } \\
\text { - Cách giao tiếp } \\
\text { - Chương trình bổ sung } \\
\text { - Quảng cáo }\end{array}$ \\
\hline 4 & $\begin{array}{l}\text { Nguyễn } \\
\text { Phương } \\
\text { Toàn } \\
(2011)\end{array}$ & $\begin{array}{l}\text { "Khảo sát các yếu tố tác } \\
\text { động đến việc chọn trường } \\
\text { của học sinh lớp } 12 \text { trung } \\
\text { học phổ thông trên địa bàn } \\
\text { tỉnh Tiền Giang" }\end{array}$ & $\begin{array}{l}\text { - Mức độ đa dạng và hấp dẫn ngành đào tạo } \\
\text { - Đặc điểm của trường đại học } \\
\text { - Khả năng đáp ứng sự mong đợi sau khi ra trường } \\
\text { - Những nỗ lực giao tiếp của trường đại học } \\
\text { - Danh tiếng của trường đại học }\end{array}$ \\
\hline
\end{tabular}




\section{4. Đề xuất mô hình nghiên cứu}

Nghiên cứu này kế thừa có chọn lọc và điều chỉnh nghiên cứu của Dao \& Thorpe (2015), kết hợp với nền tảng lý thuyết hành động hợp lý (Theory of Reasoned Action - TRA) của Ajzen \& Fishbein (1975), Thuyết hành vi và hoạch định (Theory of Planed Behavior - TPB) của Ajzen (1991), cùng với các nghiên cứu trước về ý định chọn trường của sinh viên và kết hợp với đặc điểm của trường cao đẳng Hòa Bình Xuân Lộc, đưa ra mô hình nghiên cứu đề xuất: Ý định chọn học truờng Cao đẳng nghề Hòa Bình Xuân Lộc $=f\{C o ̛$ sở vật chất và dịch vụ, Chương trình đào tạo, Chi phí, Thông tin ngoại tuyến, Các ý kiến, Thông tin trụcc tuyến, Cách giao tiếp, Chương trình bổ sung, Quảng cáo\} và các giả thuyết nghiên cứu như sau.

H1: Yếu tố co sở vật chất và dịch vụ của truờng có tác động thuận chiều đến ý định chọn truòng của sinh viên.

H2: Yếu tố chưong trình đào tạo có tác động thuận chiều đến ý định chọn truờng của sinh viên.

H3: Yếu tố chi phí có tác động thuận chiều đến ý định chọn trường của sinh viên.

H4: Yếu tố thông tin ngoại tuyến có tác động thuận chiều đến ý định chọn trường của sinh viên.
H5: Yếu tố cá nhân ảnh hưởng có tác động thuận chiều đến ý định chọn truờng của sinh viên.

H6: Yếu tố thông tin có tác động thuận chiều đến ý định chọn truờng của sinh viên.

H7: Yếu tố cách giao tiếp có tác động thuận chiều đến ý định chọn truờng của sinh viên.

H8: Yếu tố chương trình bổ sung có tác động thuận chiều đến ý định chọn trương của sinh viên.

H9: Yếu tố quảng cáo có tác động thuận chiều đến ý định chọn trường của sinh viên.

\section{KẾT QUẢ NGHIÊN CÚUU VÀ THẢO LUẬN}

\subsection{Thông tin về mẫu nghiên cứu}

Trong giai đoạn nghiên cứu định lượng chính thức, 450 sinh viên được chọn tham gia khảo sát (giai đoạn 1: sử dụng phương pháp chọn mẫu phân tầng theo tiêu thức giới tính và tôn giáo để xác định số lượng sinh viên từng nhóm tham gia vào mẫu khảo sát; giai đoạn 2 : sử dụng phương pháp chọn mẫu ngẫu nhiên đơn giản để chọn từng đáp viên trong từng nhóm tham gia nghiên cứu), và sử dụng phương pháp gửi bảng hỏi trực tiếp đến sinh viên. Kết quả thu về đủ với số lượng 450 bảng hỏi đã phát ra và tất cả đều hợp lệ (Bảng 2).

Bảng 2: Thông tin về mẫu nghiên cứu

\begin{tabular}{|l|l|c|c|}
\hline \multicolumn{2}{|c|}{ Phân loại } & Tần số & \% \\
\hline \multirow{3}{*}{ Giới tính } & Nam & 339 & 75,3 \\
\cline { 2 - 4 } & Nữ & 111 & 24,7 \\
\hline \multirow{3}{*}{ Tôn giáo } & Thiên Chúa & 356 & 79,1 \\
\cline { 2 - 4 } & Tôn giáo khác & 49 & 10,9 \\
\cline { 2 - 4 } & Không tôn giáo & 45 & 10,0 \\
\hline
\end{tabular}

\subsection{Kiểm định độ tin cậy thang đo bằng}

Nguồn: Tù kết quả xử lý SPSS

\section{Cronchbach's alpha}

Kết quả tại Bảng 3 cho thấy, sau khi loại $\mathrm{CS}_{2}$, $\mathrm{CP} 4 \mathrm{TT}_{3}$, các thang đo đều có hệ số Cronbach's Alpha khá cao $(>0,6)$, hệ số tương quan biến -

tổng lớn hơn 0,4 , do đó chúng đều được sử dụng cho phân tích EFA tiếp theo (Hà Nam Khánh Giao \& Bùi Nhất Vuơng, 2019). 
Bảng 3: Hệ số Cronbach's Alpha

\begin{tabular}{|l|c|c|c|}
\hline \multicolumn{1}{|c|}{ Biến quan sát } & Số biến quan sát & Cronbach's Alpha & $\begin{array}{c}\text { Hế số tương quan } \\
\text { biến-tống nhỏ nhất }\end{array}$ \\
\hline - Cơ sở vật chất và dịch vụ (CS) & 3 & 0,779 & 0,606 \\
\hline - Chương trình đào tạo (CT) & 4 & 0,792 & 0,551 \\
\hline - Chi phí (CP) & 3 & 0,827 & 0,647 \\
\hline - Thông tin ngoại tuyến (NT) & 4 & 0,791 & 0,569 \\
\hline - Các ý kiến (YK) & 4 & 0,840 & 0,602 \\
\hline - Thông tin trực tuyến (TT) & 2 & 0,629 & 0,465 \\
\hline - Cách giao tiếp (GT) & 3 & 0,746 & 0,535 \\
\hline - Chương trình bổ sung (BS) & 3 & 0,680 & 0,477 \\
\hline - Ý định chọn trường (YD) & 3 & 0,888 & 0,731 \\
\hline
\end{tabular}

Nguồn: Xử lý tù dũ liệu khảo sát

\subsection{Phân tích EFA}

Kết quả EFA lần thứ 7 các biến độc lập cho 26 biến quan sát ảnh hưởng đến $Y$ Ý định chọn trường, hệ số $\mathrm{KMO}$ đạt 0,621 và mức ý nghĩa (Sig. $=0,000)$ của kiểm định Bartlett's là $1 \%$ cho thấy các biến này có tương quan với nhau và hoàn toàn phù hợp với phân tích nhân tố. Giá trị eigen là $1,350>1$, với phương sai trích là $61,047 \%$ (> 50\%) cho biết 5 nhân tố giải thích được $61,047 \%$ biến thiên các dữ liệu (Bảng 4). Các biến quan sát bị loại do không đạt yêu cầu: CT3, CP3, CS4, CT2, BS2, NT4 và $\mathrm{CS} 3,19$ biến quan sát còn lại được đưa vào phân tích tiếp theo (Hà Nam Khánh Giao \& Bùi Nhất Vưong, 2019).

Bảng 4: Ma trận nhân tố đã xoay khi phân tích EFA - lần thứ bảy

\begin{tabular}{|c|c|c|c|c|}
\hline & \multicolumn{4}{|c|}{ Nhân tố } \\
\hline & 1 & 2 & 3 & 4 \\
\hline $\mathrm{CP}_{2}$ & \multirow{19}{*}{$\begin{array}{l}0,761 \\
0,756 \\
0,743 \\
0,728 \\
0,727 \\
0,629\end{array}$} & \multirow{19}{*}{$\begin{array}{l}0,778 \\
0,742 \\
0,712 \\
0,622\end{array}$} & \multirow{19}{*}{$\begin{array}{l}0,831 \\
0,828 \\
0,812 \\
0,788\end{array}$} & \multirow{19}{*}{$\begin{array}{l}0,793 \\
0,772 \\
0,697 \\
0,672 \\
0,669\end{array}$} \\
\hline $\mathbf{B S}_{1}$ & & & & \\
\hline $\mathrm{CT}_{1}$ & & & & \\
\hline $\mathrm{BS}_{3}$ & & & & \\
\hline $\mathbf{C P}_{1}$ & & & & \\
\hline $\mathrm{CT}_{4}$ & & & & \\
\hline $\mathbf{N T}_{3}$ & & & & \\
\hline $\mathbf{N T}_{2}$ & & & & \\
\hline $\mathbf{N T}_{1}$ & & & & \\
\hline $\mathrm{CS}_{1}$ & & & & \\
\hline $\mathbf{Y K}_{1}$ & & & & \\
\hline $\mathrm{YK}_{3}$ & & & & \\
\hline $\mathbf{Y K}_{4}$ & & & & \\
\hline $\mathbf{Y K}_{2}$ & & & & \\
\hline $\mathbf{G T}_{2}$ & & & & \\
\hline $\mathbf{G T}_{1}$ & & & & \\
\hline $\mathbf{G T}_{3}$ & & & & \\
\hline $\mathbf{T T}_{1}$ & & & & \\
\hline $\mathbf{T T}_{2}$ & & & & \\
\hline
\end{tabular}

Nguồn: Tổng hợp tù kết quả xử lý SPSS 
Sau khi thực hiện EFA, các thang đo mới đều có hệ số Cronbach's Alpha khá cao $(>0,6)$, hệ số tương quan biến - tổng lớn hơn 0,4, được vận dụng đặt tên cho thang đo mới (Bảng 5).

Bảng 5: Đặt tên nhân tố

\begin{tabular}{|c|c|c|c|}
\hline \begin{tabular}{c|} 
NHÂN \\
TỐ
\end{tabular} & $\begin{array}{c}\text { KÝ } \\
\text { HIỆU }\end{array}$ & BIẾN QUAN SÁT & $\begin{array}{l}\text { TÊN NHÂN } \\
\text { TỐ } \\
\end{array}$ \\
\hline \multirow{6}{*}{1} & $\mathrm{CP}_{2}$ & Tôi chọn trường này vì sự sẵn có hỗ trợ tài chính & \multirow{6}{*}{$\begin{array}{l}\text { Chi phí và } \\
\text { Chương } \\
\text { trình } \\
\text { (CРCT) }\end{array}$} \\
\hline & $\mathrm{BS}_{1}$ & Tôi chọn trường này vì có kích cỡ lớp phù hợp & \\
\hline & $\mathrm{CT}_{1}$ & $\begin{array}{l}\text { Tôi chọn trường này vì nội dung chương trình đào tạo phù hợp } \\
\text { với từng ngành học }\end{array}$ & \\
\hline & $\mathrm{BS}_{3}$ & Tôi chọn trường này vì thời khóa biểu phù hợp & \\
\hline & $\mathrm{CP}_{1}$ & Tôi chọn trường này vì học phí có thời gian thanh toán linh hoạt & \\
\hline & $\mathrm{CT}_{4}$ & Tôi chọn trường này vì các ngành học của trường dễ tìm việc làm & \\
\hline \multirow{4}{*}{2} & $\mathrm{NT}_{3}$ & Tôi chọn trường này vì có sự tư vấn trực tiếp tại nơi tôi sống & \multirow{4}{*}{$\begin{array}{l}\text { Thông tin } \\
\text { ngoại tuyến } \\
\text { và Co' sở vật } \\
\text { chất (NTCS) }\end{array}$} \\
\hline & $\mathrm{NT}_{2}$ & Tôi chọn trường này vì có cơ hội đến thăm trường & \\
\hline & $\mathrm{NT}_{1}$ & Tôi chọn trường này vì có sự liên kết với cựu sinh viên & \\
\hline & $\mathrm{CS}_{1}$ & Tôi chọn trường này vì có ký túc xá trong khuôn viên trường & \\
\hline \multirow{4}{*}{3} & $\mathrm{YK}_{1}$ & $\begin{array}{l}\text { Tôi chọn trường này theo ý kiến của các anh chị em trong gia } \\
\text { dình }\end{array}$ & \multirow{4}{*}{$\begin{array}{l}\text { Các ý kiến } \\
\text { (YK) }\end{array}$} \\
\hline & $\mathrm{YK}_{3}$ & Tôi chọn trường này theo ý kiến của giáo viên trung học & \\
\hline & $\mathrm{YK}_{4}$ & Tôi chọn trường này theo ý kiến của bạn bè & \\
\hline & $\mathrm{YK}_{2}$ & Tôi chọn trường này theo ý kiến của cha mẹ & \\
\hline \multirow{5}{*}{4} & $\mathrm{GT}_{2}$ & $\begin{array}{l}\text { Tôi chọn trường này vì có sự trao đổi qua điện thoại và trả lời tin } \\
\text { nhắn nhiệt tình từ trường }\end{array}$ & \multirow{5}{*}{$\begin{array}{l}\text { Cách giao } \\
\text { tiếp và } \\
\text { Thông tin } \\
\text { trực tuyến } \\
\text { (GTTT) }\end{array}$} \\
\hline & $\mathrm{GT}_{1}$ & Tôi chọn trường này vì có sự trao đổi với trường qua Email & \\
\hline & $\mathrm{GT}_{3}$ & $\begin{array}{l}\text { Tôi chọn trường này vì cách giao tiếp nhã nhặn lịch sự của các } \\
\text { phòng ban }\end{array}$ & \\
\hline & $\mathrm{TT}_{1}$ & $\begin{array}{l}\text { Tôi chọn trường này do tôi tìm hiều thông tin ở các trang web } \\
\text { khác }\end{array}$ & \\
\hline & $\mathrm{TT}_{2}$ & Tôi chọn trường này do tôi tìm hiểu thông tin trên mạng xã hội & \\
\hline
\end{tabular}

Nguồn: Dựa vào kết quả phân tích EFA cuối cùng

Phân tích nhân tố biến phụ thuộc Ý định chọn trường cho thấy hệ số KMO đạt 0,662 và mức ý nghĩa $(\mathrm{Sig} .=0,000)$ của kiểm định Bartlett's là $1 \%$ cho thấy các biến này có tương quan với nhau và hoàn toàn phù hợp với phân tích nhân tố. Giá trị eigen là 2,157> 1, 3 biến quan sát của biến phụ thuộc đã trích ra 1 yếu tố với tổng phương sai trích $81,963 \%$. Hệ số tải nhân tố của 3 biến quan sát này đều lớn hơn

\section{0,8 (Hà Nam Khánh Giao \& Bùi Nhất Vưong,} 2019).

3.4. Mô hình nghiên cứu điều chỉnh và các giả thuyết

Sau khi thực hiện hai giai đoạn phân tích là Cronbach's Alpha và phân tích nhân tố EFA lần lượt cho thang đo các yếu tố ảnh hưởng đến ý định chọn tường và thang đo "Ý định chọn trường”, mô hình nghiên cứu được 
điều chỉnh: Ý định chọn học trường Cao đẳng nghề Hòa Bình Xuân Lộc =f\{ Chi phí và chưong trình, Thông tin ngoại tuyến và cơ sở vật chất, Các ý kiến, Cách giao tiếp và thông tin trục tuyến\} và các giả thuyết nghiên cứu điều chỉnh như sau.

$H_{1}$ : Yếu tố "Chi phí và Chương trình" có quan hệ cùng chiều với thành phần "Ý định chọn truò̀ng”.

$\mathrm{H}_{2}$ : Yếu tố "Thông tin ngoại tuyến và Co" sở vật chất" có quan hệ cùng chiều với thành phần "Ý định chọn truờng".
$H_{3}$ : Yếu tố "Các ý kiến" có quan hệ cùng chiều với thành phần "Ý định chọn truòng".

$H_{4}$ : Yếu tố "Cách giao tiếp và Thông tin trực tuyến" có quan hệ cùng chiều với thành phần "Ý định chọn truò̀ng".

\subsection{Phân tích tương quan}

Để xem xét mối quan hệ tương quan tuyến tính giữa các biến độc lập CPCT, NTCS, YK, GTTT và biến phụ thuộc YD, kiểm định hệ số tương quan Pearson được sử dụng. Kết quả phân tích tương quan cho thấy tất cả các biến đều có tương quan với nhau tại mức ý nghĩa 1\% (Bảng 6).

Bảng 6: Ma trận tuoong quan giữa biến phu thuộc và biến độc lập

\begin{tabular}{|c|c|c|c|c|c|}
\hline & $\begin{array}{l}\text { Chi phí và } \\
\text { Chương } \\
\text { trình }\end{array}$ & $\begin{array}{c}\text { Thông tin } \\
\text { ngoại tuyến và } \\
\text { Cơ sở vật chất }\end{array}$ & Các ý kiến & $\begin{array}{c}\text { Cách giao tiếp } \\
\text { và Thông tin } \\
\text { trụcc tuyến }\end{array}$ & $\begin{array}{l}\text { Ý định } \\
\text { chọn } \\
\text { trường }\end{array}$ \\
\hline Chi phí và Chương trình & 1 & & & & \\
\hline $\begin{array}{l}\text { Thông tin ngoại tuyến và } \\
\text { Cơ sở vật chất }\end{array}$ & $\begin{array}{c}0,345 * * \\
0,000\end{array}$ & 1 & & & \\
\hline Các ý kiến & $\begin{array}{c}0,135 * * \\
0,004\end{array}$ & $\begin{array}{c}0,106^{*} \\
0,025\end{array}$ & 1 & & \\
\hline $\begin{array}{l}\text { Cách giao tiếp và Thông } \\
\text { tin trực tuyến }\end{array}$ & $\begin{array}{l}0,079 \\
0,093\end{array}$ & $\begin{array}{c}0,117^{*} \\
0,013\end{array}$ & $\begin{array}{l}0,007 \\
0,878\end{array}$ & 1 & \\
\hline Ý định chọn trường & $\begin{array}{c}0,774 * * \\
0,000\end{array}$ & $\begin{array}{c}0,479 * * \\
0,000\end{array}$ & $\begin{array}{c}0,211 * * \\
0,000\end{array}$ & $\begin{array}{l}0,076 \\
0,108\end{array}$ & 1 \\
\hline
\end{tabular}

** Correlation is significant at the 0,01 level $(2$ - tailed $)$

* Correlation is significant at the 0,05 level $(2-$ tailed $)$

\subsection{Phân tích hồi qui bội}

Từ Bảng 7 , kết quả ANOVA cho thấy trị thống kê $\mathrm{F}$ của mô hình $=287,564$ với mức ý nghĩa $1 \%(\operatorname{sig}=0,000)$, cho thấy mô hình hồi quy tuyến tính bội phù hợp với tập dữ liệu hay các biến độc lập có quan hệ tuyến tính với biến phụ thuộc và mô hình có thể sử dụng được. Mô hình có hệ số $\mathrm{R}^{2}$ hiệu chỉnh là 0,657 , hay $65,7 \%$ mức độ biến thiên Ý định chọn trường được giải thích bởi các biến độc lập.

Kết quả hồi quy cũng cho thấy: có 3 biến có ý nghĩa thống kê ở mức 1\% (Sig. $\leq 0,01)$, mô hình lý thuyết phù hợp với dữ liệu nghiên cứu, và có 03 giả thuyết nghiên cứu được chấp nhận (Hà Nam Khánh Giao \& Bùi Nhất Vương, 2019). Yếu tố "Cách giao tiếp và thông tin trực tuyến” không có ý nghĩa thống kê. Phương trình hồi quy chưa chuẩn hóa có dạng: Ý định chọn học trưòng Cao đẩng nghề Hòa Bình Xuân Lộc $=-0,894+0,922 *$ Chi phí và Chuoong trình + 0,254*Thông tin ngoại tuyến và Cơ sở vật chất $+0,082 *$ Các ý kiến. 
Bảng 7: Hệ số hồi quy

\begin{tabular}{|c|c|c|c|c|c|c|c|c|}
\hline \multirow{2}{*}{\multicolumn{2}{|c|}{ Mô hình }} & \multicolumn{2}{|c|}{$\begin{array}{c}\text { Hệ số hồi quy chưa } \\
\text { chuẩn hóa }\end{array}$} & \multirow{2}{*}{$\begin{array}{l}\text { Hệ số hồi quy } \\
\text { chuẩn hóa } \\
\text { Beta }\end{array}$} & \multirow[t]{2}{*}{$\mathbf{T}$} & \multirow[t]{2}{*}{ Sig. } & \multicolumn{2}{|c|}{$\begin{array}{c}\text { Thống kê đa cộng } \\
\text { tuyến }\end{array}$} \\
\hline & & B & Sai số chuẩn & & & & Độ chấp nhận & VIF \\
\hline \multirow{4}{*}{1} & Hằng số & $-0,894$ & 0,167 & & $-0,358$ &, 000 & & \\
\hline & СРCT & 0,922 & 0,040 & 0,680 & 22,976 &, 000 & 0,871 & 1,148 \\
\hline & NTCS & 0,082 & 0,032 & 0,235 & 7,956 &, 000 & 0,878 & 1,140 \\
\hline & YK & 0,266 & 0,024 & 0,095 & 3,385 & ,001 & 0,978 & 1,023 \\
\hline
\end{tabular}

$\mathrm{R}^{2}$ hiệu chỉnh: 0,657

Thống kê Durbin-Watson: 1,925

Thống kê F (ANOVA): 287,564

Mức ý nghĩa (Sig. của ANOVA): 0,000

Nguồn: Phân tích tù dũ liệu thu thập

Yếu tố "Cách giao tiếp và Thông tin trực tuyến" không có ý nghĩa thống kê do có Sig = $0,818>0,1$. Từ nội hàm của yếu tố này (Bảng 5), có thể thấy điều này khá hợp lý trong thực tiễn, đây là trường tôn giáo hoạt động trong lĩnh vực giáo dục, mô hình này còn khá mới mẻ tại Việt Nam, các kênh thông tin quảng bá trường chủ yếu đến từ các nhà thờ nơi có cộng đoàn giáo dân sinh sống, vì vậy đa phần người có tôn giáo Thiên Chúa sẽ biết thông tin và tham gia học, với một niềm tin cao.

\subsection{Kiểm định các giả định hồi quy}

Trong việc dò tìm sự vi phạm các giả định hồi quy tuyến tính: biểu đồ phân tán Scatterplot cho thấy phần dư không thay đổi theo một trật tự nào đối với giá trị dự đoán, chúng phân tán ngẫu nhiên, giả thuyết về liên hệ tuyến tính không bị vi phạm. Hệ số tương quan hạng Spearman của giá trị tuyệt đối phần dư và các biến độc lập: giá trị Sig. của các hệ số tương quan với độ tin cậy $95 \%$ đều lớn hơn 0,05 , cho thấy phương sai của sai số không thay đổi, giả định không bị vi phạm. Biểu đồ Histogram cho thấy phần dư có phân phối chuẩn với giá trị trung bình rất nhỏ gần bằng $0($ Mean $=3.97 \mathrm{E}-15)$ và độ lệch chuẩn của nó gần bằng $1(\mathrm{SD}=0,0,989)$, đồ thị P-P plot biểu diễn các điểm quan sát thực tế tập trung khá sát đường chéo những giá trị kỳ vọng, có nghĩa là dữ liệu phần dư có phân phối chuẩn. Hệ số $1<$ Durbin -Watson $=1,925<3$ là thỏa điều kiện, hệ số phóng đại phương sai VIF $<10$ cho thấy các biến độc lập không có quan hệ chặt chẽ với nhau nên không xảy ra hiện tượng đa cộng tuyến. Như vậy, mô hình hồi quy tuyến tính được xây dựng theo phương trình trên không vi phạm các giả định hồi quy (Hà Nam Khánh Giao \& Bùi Nhất Vurong, 2019).

\subsection{Kiểm định sự khác biệt}

Kiểm định t-test cho thấy không có sự khác biệt về Ý định chọn trường giữa nam và nữ. Kiểm định ANNOVA cho thấy không có sự khác biệt về Ý định chọn trường giữa các nhóm tôn giáo khác nhau, do đây là trường Công giáo nên số sinh viên Công giáo trong mẫu nghiên cứu chiếm tỷ trọng lớn $(79,1 \%)$ so với các tôn giáo khác $(10,9 \%)$ và không tôn giáo (10\%) (Bảng 1).

\subsection{So sánh kết quả nghiên cứu với các nghiên cứu trước}

Bảng 8 cho thấy một phần so sánh với kết quả các nghiên cứu trước. Thật ra, các yếu tố so sánh trong các nghiên cứu là không đồng nhất, bắt nguồn từ việc thừa kế, rút trích thang đo, và điều chỉnh thang đo cho phù hợp với điều kiện trường Cao đẳng nghể Hòa Bình Xuân Lộc. Tuy nhiên, những so sánh như vậy cũng giúp gợi ý cho việc đề xuất những hàm ý quản trị. 
Bảng 8: So sánh với kết quả các nghiên cưu trước

\begin{tabular}{|l|c|c|c|}
\hline & $\begin{array}{c}\text { Nghiên cứu } \\
\text { hiện tại }\end{array}$ & $\begin{array}{c}\text { Chapman } \\
\text { (1981) }\end{array}$ & $\begin{array}{c}\text { Nguyễn Phương } \\
\text { Toàn (2011) }\end{array}$ \\
\hline Chi phí và chương trình & 1 & 2 & 2 \\
\hline Thông tin ngoại tuyến và Cơ sở vật chất & 2 & 3 & 1 \\
\hline Các ý kiến & 3 & 1 & 0 \\
\hline
\end{tabular}

Ghi chú: "0". không có trong nghiên cưu, "1". tác động mạnh nhất, "2”. tác động thư hai, "3”. tác động thứ ba.

\section{KẾT LUẬN VÀ ĐỀ XUẤT HÀM Ý QUẢN TRI}

\subsection{Kết luận}

Qua quá trình nghiên cứu, nhóm tác giả đã sử dụng phương pháp nghiên cứu định lượng phù hợp, xử lý số liệu bằng phương tiện thống kê để có thể xác định được 03 yếu tố tác động đến ý định chọn trường của sinh viên, sắp theo tứ tự giảm dần: Chi phí và Chương trình $(\beta=$ $0,922)$, Thông tin ngoại tuyến và Cơ sở vật chất $(\beta=0,254)$, Các ý kiến $(\beta=0,131)$.

\section{2. Đề xuất hàm ý quản trị}

\subsubsection{Nhóm yếu tố "Chi phí và chương trình"}

Nhìn chung, SV đánh giá khá cao đối với các thành phần sử dụng để đo lường yếu tố "Chi phí và chương trình" (giá trị trung bình thấp nhất là 3,73$)$. Nhà trường cần có biện pháp khắc phục tình trạng sĩ số lớp đông: xây dựng và mở rộng quy mô các phòng học, phòng học không cần quá lớn nhưng phải đủ rộng để đảm bảo thoáng mát, sạch sẽ kết hợp với số lượng sinh viên vừa đủ nhằm nâng cao sự tập trung, có sự tương tác đầy đủ giữa người dạy và người học, tăng cường số lượng đội ngũ giảng viên để đảm bảo tiến độ giảng dạy. Bên cạnh đó, Trường Cao đẳng nghề Hòa Bình Xuân Lộc có thế mạnh là luôn được các nhà hảo tâm và các doanh nghiệp quan tâm hỗ trợ, vì vậy việc kêu gọi các mạnh thường quân hỗ trợ kinh phí để đảm bảo nguồn kinh phí xây dựng là cần thiết và khả thi trong giai đoạn hiện nay.

Nhà trường cần xây dựng thời khóa biểu khoa học, không nên dồn tất cả các môn học chung (Chính trị, pháp luật, giáo dục thể chất, giáo dục quốc phòng...) vào học kỳ đầu tiên mà phân bổ đều qua các học kỳ trong chương trình, nhằm tránh sự nhàm chán và giúp sinh viên có hứng thú hơn khi được tiếp xúc sớm với các môn học thuộc các ngành học. Bên cạnh đó, Nhà trường có thể cân nhắc cho sinh viên học thêm thứ 7 nhằm giảm tải việc học dồn ở các ngày trong tuần, đồng thời giải quyết được vấn đề thiếu phòng học và phòng thực hành. Đối với những ngành học có số lượng sinh viên đông, phòng thực hành không đủ để đáp ứng, có thể xây dựng thời khóa biểu học $3 \mathrm{ca} /$ ngày.

Nhà trường cần tiếp tục duy trì, đồng thời tăng cường quan hệ hợp tác với các doanh nghiệp trong việc hỗ trợ các nguồn học bổng dành cho sinh viên. Bên cạnh đó, cần theo dõi các chính sách hỗ trợ của nhà nước, có thông báo rộng rãi, nhiệt tình hướng dẫn để sinh viên thực hiện các thủ tục vay vốn ưu đãi, miễn giảm học phí đối với những sinh viên thuộc các trường hợp theo Quyết định 157/2007/QĐ-TTg.

Nhà trường cần tiếp tục phát huy và mở rộng quy mô tuyển sinh các ngành nghề là mũi nhọn, thế mạnh của trường. Phát triển ngành đào tạo mới đáp ứng nhu cầu xã hội và hội nhập quốc tế, đặc biệt các ngành về khoa học ứng dụng, công nghệ cao hoặc mang tính phối hợp liên ngành. Thay đổi phương pháp đào tạo, chương trình đảm bảo những ngành nghề này đáp ứng tiêu chí, tiêu chuẩn quy định nghề trọng điểm quốc gia.

Bên cạnh đó, chú trọng đào tạo kỹ năng mềm, tin học và ngoại ngữ phù hợp với từng chuyên ngành nhằm tăng cơ hội chuyển đổi kiến 
thức, liên thông giữa các bậc học đáp ứng nhu cầu học tập suốt đời của người học. Ngoài ra, xây dựng mô hình "đào tạo kép" kết hợp đào tạo giữa doanh nghiệp và nhà trường, tích hợp giữa lý thuyết và thực hành, tăng cường thời lượng thực hành của sinh viên tại doanh nghiệp, hạn chế việc học lý thuyết đơn thuần, thu thập thông tin về sinh viên trong quá trình thực tại doanh nghiệp bằng bảng khảo sát nhằm kịp thời phát hiện những bất cập trong việc đào tạo, điều chỉnh giáo trình có sự tham vấn của các doanh nghiệp, các chuyên gia, giảng viên và cán bộ quản lý giáo dục nhằm đáp ứng chuẩn kiến thức, kỹ năng của người học đạt được sau khi tốt nghiệp.

Đối với đội ngũ giảng viên, cần tiếp cận phương pháp giảng dạy tiên tiến, phát huy tính sáng tạo của người học, thường xuyên có các khóa học thực hành định kỳ tại các doanh nghiệp nhằm tiếp cận kịp thời với khoa học công nghệ luôn đổi mới.

\subsubsection{Nhóm yếu tố "Thông tin ngoại tuyến và cơ sở vật chất"}

Đánh giá của sinh viên đối với hoạt động tư vấn, cơ hội tiếp xúc với nhà trường và sự kết nối với cựu sinh viên tương đối cao. Nhà trường cần tích cực hơn nữa trong việc triển khai các hoạt động tư vấn tuyển sinh trực tiếp tại địa phương, đây là kênh thông tin quan trọng để sinh viên có cơ hội tiếp cận và tìm hiểu về ngôi trường mà mình muốn theo học. Vì vậy, trước mỗi kỳ tuyển sinh, đòi hỏi phải có sự chuẩn bị kỹ lưỡng các thông tin mà Nhà trường muốn truyền tải đến sinh viên, đồng thời có sự lựa chọn đội ngũ tư vấn viên chuyên nghiệp, có nhiều kinh nghiệm và kỹ năng giao tiếp tốt, có khả năng truyền đạt thông tin và tạo sự tin tưởng từ phía sinh viên và phụ huynh. Nhà trường cần có những chính sách hỗ trợ về tài chính một cách hiệu quả đối với đội ngũ giảng viên, cán bộ và nhân viên, những người tiếp xúc trực tiếp với sinh viên và phụ huynh trong vai trò tư vấn tuyển sinh.
Nhà trường cần có sự liên kết chặt chẽ với cựu sinh viên, lập kế hoạch thu thập thông tin về việc làm, thu nhập của sinh viên sau khi tốt nghiệp, tạo sự gắn kết cựu sinh viên với sinh viên và nhà trường, đây được xem là cầu nối truyền thông và nguồn hỗ trợ địa điểm thực tập cũng như việc làm tốt nhất để thu hút sinh viên. Muốn được như vậy, Nhà trường cần có các hoạt động cụ thể dành cho cựu sinh viên, thu thập thông tin và tuyên dương những cựu sinh viên thành đạt trong xã hội, có nhiều đóng góp tích cực cho Nhà trường.

Nhà trường cần chú trọng hơn nữa đến việc cải thiện khu ký túc xá an toàn, thoáng mát, sạch đẹp, bố trí thêm nhiều góc học tập để phục vụ việc tự học của sinh viên, thường xuyên phân công đội ngũ bảo vệ túc trực, đội ngũ bảo trì để kịp thời sửa chữa, khắc phục những vấn đề phát sinh, phục vụ tốt nhu cầu ăn ở của sinh viên.

Nhà trường cần tiếp tục duy trì và phát huy hơn nữa công tác hỗ trợ và tạo điều kiện để học sinh đến thăm quan, học sinh được trực tiếp tiếp xúc với các Khoa chuyên môn, phòng, ban chức năng, thăm quan khu phòng học lý thuyết và thực hành, ký túc xá, điều này sẽ càng củng cố hơn cho ý định của sinh viên.

\subsubsection{Nhóm yếu tố “Các ý kiến”}

Đối với yếu tố "Các ý kiến” mức đánh giá chung của sinh viên trên mức trung bình $(2,79)$. Nhà trường cần có sự tiếp cận tốt đối với đối tượng là các thầy cô, bạn bè trung học của sinh viên, đây là đối tượng tác động khá mạnh đến ngay cả học sinh và phụ huynh. Nhà trường cần hoạt động tích cực hơn trong việc liên hệ, tạo mối quan hệ với các trường trung học phổ thông, tổ chức các chương trình mang tính học thuật và chuyên môn, có cơ hội tiếp xúc với các học sinh và giáo viên tại các trường thuộc địa bàn tuyển sinh nhằm quảng bá hình ảnh của trường. Bên cạnh đó, cần có sự theo dõi và kiểm soát thông tin bất lợi, giải quyết nhanh và thỏa đáng với các thắc mắc của các đối tượng quan tâm đến trường. 
Nhà trường cần tiếp tục duy trì sự hợp tác chặt chẽ với phụ huynh học sinh, nhiệt tình tư vấn và hỗ trợ khi họ có nhu cầu tìm hiểu thông tin về trường. Thường xuyên liên hệ tạo mối quan hệ gắn kết giữa gia đình và Nhà trường, có sự phản hổi về tình hình học tập, thông báo về sự thay đổi (nếu có) các chính sách liên quan đến chương trình đào tạo cho phụ huynh nhằm tạo sự an tâm cho các gia đình khi có con em học tập tại trường.

\subsection{Các hạn chế của nghiên cứu và hướng nghiên cứu tiếp theo}

Nghiên cứu đã đạt được các mục tiêu nghiên cứu đã đề ra nhưng vẫn còn những hạn chế nhất

\section{TÀI LIẸU THAM KHẢO}

[1]. Ajzen, I. (1991), The Theory of Planned Behavior, Organizational Behavior and Human Decision Process, 50, 179-211.

[2]. Ajzen, I., \& Fishbein, M. (1975), Belief, Attitude, Intention, and Behavior. AddisonWesley Publishing Company, Inc.

[3]. Alexander, K. L., \& Eckland, B. K. (1975), Basic attainment processes: A replication and extension. Sociology of Education, 48(4), 457-495.

[4]. Chapman, D.W. (1981), A model of student college choice, The Journal of Higher Education, 52 (5), 490-505.

[5]. Chapman, R. G., \& Jackson, R. (1987), College choices of academically able students: The influence of no-need financial aid and other factors. New York, NY: College Entrance Examination Board.

[6]. Dao, Mai Thi Ngoc \& Anthony Thorpe (2015), What factors influence Vietnamese students' choice of university, International Journal of Education Management, 29 (5), 666-681.

[7]. Garrett, M. (2006). The identity of American Catholic higher education: A historical overview, Journal of Catholic Education, 10 (2), 229 -247. định: Thư nhất, còn nhiều yếu tố khác ảnh hưởng đến ý định chọn Trường Cao đẳng nghề Hòa Bình Xuân Lộc mà nghiên cứu chưa tìm ra. Vì vậy, nghiên cứu tiếp theo cần nghiên cứu định tính sâu hơn để tìm ra một số yếu tố mới ảnh hưởng đến ý định chọn trường của sinh viên. Thư hai, mô hình nghiên cứu về trường công giáo đào tạo nghề còn khá mới mẻ tại Việt Nam, các thang đo sử dụng đa số từ các nước mà mô hình này rất phổ biến, nên vấn đề điều chỉnh thang đo còn nhiều vấn đề cần bàn trong nghiên cứu này. Nghiên cứu tiếp theo cần làm tốt hơn về nghiên cứu định tính và nghiên cứu định lượng sơ bộ để điều chỉnh thang đo hợp lý hơn.

[8]. Hà Nam Khánh Giao - Bùi Nhất Vương. (2019). Giáo trình cao học - Phương pháp nghiên cứu khoa học trong kinh doanh - Cập nhật SmartPLS. Nhà xuất bản Tài chính. DOI: 10.31219/osf.io/hbj3k.

[9]. Hà Nam Khánh Giao (2018). Sách chuyên khảo Đo lường chất lượng dịch vụ- Nhìn từ phía khách hàng. Nhà xuất bản Tài chính. Hà Nội. DOI: 10.31219/osf.io/cqh68.

[10]. Henry, L.M. (2012), Understanding the college choice process of catholic homeschooled students, Doctoral dissertation, Education, Kansas, USA.

[11]. Hossler, D., \& Gallagher, K. S. (1987), Studying student college choice: A three-phase model and the implications for policymakers, College and University, 62(3), 207-221.

[12]. Nguyễn Phương Toàn (2011), Khảo sát các yếu tố tác động đến việc chọn truờng của hoc sinh lớp 12 trung hoc phổ thông trên địa bàn tỉnh Tiền Giang, Luận văn Thạc sĩ Đo lường và Đánh giá trong giáo dục, Viện Đảm bảo chất lượng giáo dục - Đại học Quốc gia Hà Nội.

[13]. Sewell, W. H., Haller, A. O., \& Portes, A. (1969), The educational and early occupational attainment process, American Sociological Review, 34(1), 82-92. 